Journal of Economics and Behavioral Studies

Vol. 5, No. 8, pp. 546-552, Aug 2013 (ISSN: 2220-6140)

\title{
The application of the theory of Visitor Attractions and its impact on the competitive advantage of the Tourism Sector in Durban, South Africa
}

\author{
*R Balkaran \& S Maharaj \\ Durban University of Technology, South Africa \\ *rishi@dut.ac.za
}

\begin{abstract}
Visitor attractions become the nexus in the relationship between the Tourism sector and the city of Durban as a competitive destination and are arguably the most significant component within the tourism system. To become competitive within the attraction sector there is a need to have a combination of attractions, like sightseeing, shopping, entertainment, gaming, culture and recreation and these plays an important role in determining the competitiveness of a destination. The increase in tourist activity creates an environment where all stakeholders within the tourism system have an opportunity to exercise their function in the most appropriate way. This however does not occur without challenges and clearly, from general observations, the Tourism sector is faced with several challenges in Durban such as the lack of synergy between the stakeholders within the tourism system; standards and quality between various groups differ which impact on service delivery, price structure and foreign expectations; sustaining a high cost capital and labour intensive industry throughout the year; domestic tourists having to compete with currency fluctuations; and the social, political, economic and technological challenges. The development of a competitive model would contribute to tourism sustainability, which is vital for the economy, growth and further development of the Tourism sector in Durban, South Africa.
\end{abstract}

Keywords: Visitor attraction, Tourism, Competitive advantage, Stakeholders

\section{Introduction}

The purpose for the above study has emerged from an analysis of various long term marketing strategies and destination competitiveness models from the United Nations World Tourism Organization (hereafter referred to as UNWTO), National Department of Tourism ((hereafter referred to as NDT), South African Tourism ((hereafter referred to as SAT), Durban Tourism, Tourism KwaZulu-Natal ((hereafter referred to as TKZN), The Chamber of Commerce and EThekwini Municipality. The result of this analysis is that Durban does not have a long-term marketing strategy or a destination competitiveness model. Hence, the purpose of this study is a destination competitiveness model would contribute to a long-term strategy contributing to tourism sustainability, which is vital for the economy, growth and further development of tourism in Durban. The development of a destination competitiveness model will allow tourism stakeholders to identify key strengths and weaknesses, highlight opportunities for visitor attraction development, and develop strategies to capitalize on these opportunities and to counter possible threats to future visitor attraction developments. Macfarlane (2012) states that Durban's current visitor attraction issues such as a value for money destination, distribution, promotion, knowledge, relevance and access. This document reveals that Durban visitor numbers have declined, that there is lack of demand for the city, enormous economic, social and community costs therefore. There is also a lack of online tourism information available. Durban's tourism competitiveness model must be based on the UNWTO, SAT and TKZN models which are international and national tourism governing bodies. Durban's core visitor attractions such as cultural elements, physiography, activities, special events, uniqueness, entertainment, tourism superstructure, infrastructure, transportation, hospitality, entertainment, accessibility, location, safety and security destination appeal, technology, social media, attractions, natural resources and market segments. The following marketing aspects are vital: destination awareness and image, destination branding and experience, brand effectiveness, visitor experience and visitor services. Creating memorable experiences can create a clear competitive advantage and destination appeal. Customer experience rather than customer service is a hallmark of new economic growth. 


\section{The Theory of Visitor Attractions}

Goeldner et al. (2000) advance that attractions are the reason why people travel thereby making it the single, most significant component of the tourism system and without attractions drawing people to destinations, there would be little need for tourism services such as transportation, lodging, food and others. The key observation made by Goeldner et al. (2000), in respect of attractions is that it draws the smallest portion of the tourist expenditure with the majority of the disbursements going to air transportation, accommodation and food. To become competitive within the attraction sector there is a need to have a combination of attractions, like sightseeing, shopping, entertainment, gaming, culture and recreation and this play an important role in determining the competitiveness of a destination (Goeldner, Ritchie \& Mcintosh, 2000). Swarbrooke (2002), states that the definition of visitor attractions has evolved over the years and concludes that it remains a complex one. He identifies one of the more recent definitions of attractions by Heron \& Stevens (1990) as being reflective of developments that are more recent. This definition is as follows: A visitor attraction is a feature in an area that is a place, venue, or focus of activities and does the following things:

- $\quad$ sets out to attract visitors/day visitors from resident or tourist populations, and is managed accordingly;

- provides a fun and pleasurable experience and an enjoyable way for customers to spend their leisure time;

- is managed as an attraction, providing satisfaction to its customers;

- provides an appropriate level of facilities and services to meet and cater to the demands, needs, and interests of its visitors; and

- may or may not charge an admission for entry.

According to Swarbrooke (2002), this definition excludes the uncontrollable and unmanageable situations that are often referred to as attractions, such as climate. He further comments that not only is the attraction sector a diverse and complex one, it is further geographically segmented with the segments having their own interpretations and approaches to these attractions and therefore making it extremely difficult for a systematised method of collecting data in these niches. However, he expounds that one can accept that attractions are single, accessible, and small-scale geographic units that have the capacity to attract large numbers of people to travel some distance from their homes. This is usually during their leisure time with their visit being for a short and limited period. Tourist attraction is seen as the base of tourism (Bennett, 1995: 8). People would have very little motivation to visit a tourist destination that has no attraction. Bennett (1995: 9) lists three categories of attractions namely, natural attractions, man-made attractions and sociocultural attractions. George (2001) states that attractions play a key role in tourism and hospitality destinations and that they entice the visitors to the destination. George (2001) makes mention of A primary attractions $\Theta$, which are those, that are in themselves sufficient to induce the tourist to visit the destination and secondary attractions which are not important enough to convince them, but which can serve as a complementary feature. Historical sights, archeological sites, architecture, cuisine, monuments, industrial sites, museums, concerts, ethnic, and theatre are examples. Landscapes, seascapes, parks, mountains, flora, fauna, coasts and islands are examples of natural attractions.

Mega-events, community events, festivals, religious events, sports events, trade shows and corporate events are examples of events. Major sporting events like the World Cup Cricket and advanced sporting facilities boosts the attraction base within KZN. The International Convention Centre (ICC) Durban has hosted numerous International conferences and events. The Tourism Indaba hosted at the Durban's ICC is cited as one of the world's top events hosted at the Durban's ICC (The KZN Review: Industry, Commerce and Tourism, 2000/2001: 47). Sightseeing, sport, hiking and snow sports are examples of the recreation attractions. According to Goeldner et al. (2000), entertainment attractions include theme or amusement parks, which have their roots in medieval Europe where pleasure gardens were created. He says that these gardens have set the pace for the establishment of theme parks today, like the famous Disney World in the United States and the budding Rotunda Junction in Cape Town. Comparative advantage refers to a destinations natural endowment in factors of production, the resource that makes a destination attractive. Competitive advantage refers to a destinations ability to use those resources effectively. Durban as a destination needs to use it's 
natural and man-made resources effectively in enhancing its destination competitiveness.

\section{The significance of Competitiveness of visitor attractions in Durban as a destination}

Keyser (2009) states that a destination can be described as "a defined spatial area made up of a mix of tourism resources, created facilities and support services and infrastructure, that are managed, marketed and consumed under a single brand identity." Keyser (2009) confirms that Destination Competitiveness is "the ability of a destination to provide satisfactory visitor experiences, while simultaneously maintaining and expanding the standards of living of its population." A model looks at the theoretical frame and a strategy is a guiding framework. Tourism is a people dependant industry. Competitiveness brings about sustainability of a destination. The Travel and Tourism Competitiveness Report 2013 focuses on reducing barriers t economic growth and job creation. "South Africa is ranked 3rd in the region and 64th overall, gaining two places since the last edition. South Africa comes in high at 17th place for its natural resources and 58th for its cultural resources, based on its many World Heritage sites, its rich fauna, its creative industries, and the many international fairs and exhibitions held in the country. Infrastructure in South Africa is also well developed for the region, with air transport infrastructure ranked 43rd and a particularly good assessment of railroad quality (46th) and road" (Source: The Travel and Tourism Competitiveness Report 2013).

The Global Tourism Competitiveness report (2011(21/41) which was developed by the UNWTO indicates that SA ranked 66 out of 139 countries. Areas of concern were health, safety and security. Structural longterm shifts focus on strategic destination development, cooperation between public and private sectors, promote open market environment, diversify source markets, and promote strong domestic tourism, plan sustainable infrastructure. The Global Tourism Competitiveness report (2009) which is developed by the UNWTO focuses on terrorism and economic recession, which is linked with spending and high fuel costs. All the above-mentioned factors need to be taken into consideration when a long-term marketing strategy and competitiveness model is developed for Durban. The United Nations World Tourism Organization White Paper (2011) proposes five priority areas to concentrate it's work regarding increasing competitiveness and ensuring sustainability. These include areas of tourism sustainability, market trends and forecasting, destination management and marketing, quality, safety and security. The South African White Paper on Tourism (May 1996) focuses on igniting the engine of tourism growth. Elements of tourism competitiveness are discussed in this section, which focuses on sustainability of culture, environment, marketing and promotion, co-operation and product development. The White Paper on the Development and Promotion of Tourism in KwaZulu-Natal (March 2008(49), price, infrastructure development, environmental quality, technology advancement and social development. Establishing Durban's competitiveness factors will ensure that the cities marketing strategy encompasses global, national and regional competitiveness factors thus ensuring sustainability. Crouch (2011) suggests that tourism destinations need to develop maintain, protect and strengthen their competitive positions at a global level. Therefore determining the destination competitive advantages of Durban are vital for it is sustainability. Crouch (2007) endorses on the attributes of competitiveness. The purpose of the development of a sustainable model for Durban as a competitive tourism destination is to develop economic growth, job creation, destination appeal and sustainability.

\section{How would Durban's visitor attractions contribute to the competitiveness of Durban's tourism industry?}

The development of a competitiveness model for Durban would assist tourism stakeholders in their long term marketing strategies, which would ensure that the city is a preferred destination. Visitor attractions are a vital component of developing destinations, which is a major component that attracts tourists. Destination competitiveness models developed on an international level by Ritchie and Crouch (2003) focuses on the destinations development of tourism, which must be sustainable, focus on long term prosperity, industry level, attributes, mainstreams and tourism destination attractiveness. In Dwyer and Kim's integrative model (2003), comparative advantage refers to a destination's natural endowment in factors of production, the resources that make the destination attractive. The two models developed also demonstrate best practice on a global platform in the international market. The use of a competitiveness model will assist with long-term marketing strategies; increase tourist volumes to the city, increase spending power, which would create economic prosperity, job creation, to ensure that all tourism resources are adequately marketed and to create 
destination appeal by providing unique memorable destination experiences.

Figure 1. Integrated Model of Destination Competitiveness

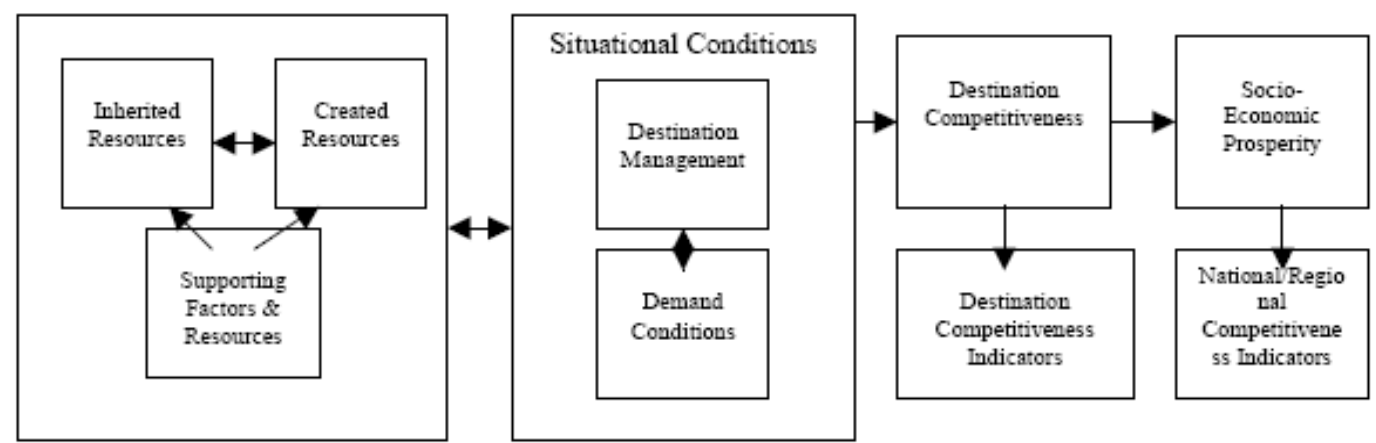

Source: Dwyer and Kim (2003, p: 12)

As demonstrated in the above diagram visitor attractions have a competitive impact in the tourism sector as the inherited and core resources of a destination are the contributing factors of destination appeal and are the foundation for a successful tourism industry. In order for Durban to be a competitive destination, it should offer safe, affordable and efficient transportation in term of road, rail, sea and air transportation. Crouch (2011:27) states that tourism destination needs to develop, maintain, protect and strengthen their competitive positions at a global level therefore determining a destinations competitive advantages is vital for it is sustainability. Crouch (2007:429) model focuses on the attributes of competitiveness. Durban's attributes would be it's natural, man-made attractions and it's mixture of cultures. Durban has adequate resources and attractions to draw local and international tourists. Durban can gain competitive advantage by marketing it's rich mixture of cultures, have more hallmark iconic events, water-based and sporting and leisure recreation events, activities experiences. Durban has an established Convention Bureau that focuses on conferences, meetings and business tourism. Durban's Golden Mile needs an improvement in terms of regaining Blue Flag beach status appearance, entertainment and thing to see and do. Durban's competitiveness factors would be established by assessing the cities tourism product (visitor attractions) and other contributing factors such as pricing, place, promotion, people, physical evidence and process. Lockwood and Medlik (2002: 203) states that there are traditional and new attractions and indicates that there is a need for leisure and entertainment. Connell \& Page (2009:373) states that visitors to attractions are now seeking good quality facilities at competitive prices, greater interaction seeking integration of technology and high touch exhibits with a greater degree of social interaction whist visiting attractions.

Yeoman (2008:39) states that tourists by the year 2030 will desire eco-stress free experiences; enjoy new experiences, culture and authenticity. Ham \& Weile (2002:254) discusses that tours should vary widely in terms of duration of tour, length of stay, location, type of attraction, transportation, terrain and clientele. Durban as a destination has many man-made and natural attractions however there needs to be deployment of these attractions. Chen and Uysal (2002:29(4)988-1000) further propose that important resources at the destination should be identified and positioned according to that of the competitors which would be vital for long-term success. Durban as a destination needs to ensure that it is a value for money destination. Durban Tourism must ensure exposure of Durban using various distribution channels to create awareness. Mason (2009(48),139)states that the travel blog narratives are becoming increasingly important as they indicate their satisfaction levels of the destination and recommend the destination to other tourists. Durban must ensure that it creates destination appeal to attract both domestic and international tourists according to the following authors. Hong, Lee, Jang \& Woo (2009(36), 268) suggest that tourists would revisit a destination based on its appeal, experience and satisfaction during the first visit. Ekinci, Nam\& Whyatt (2011:3(38), 1009) suggest that customer satisfaction is essential for long term success. It's dependant on staff behaviour, brand identification and brand loyalty. Decrop $(2009(37), 93)$ state that formation and destination choices are vital because tourists have a range of choices available to them, therefore the need for distinct destination appeals and experiences. 


\section{Figure 1: Visitor attraction factors that would contribute to Durban's tourism competitiveness}

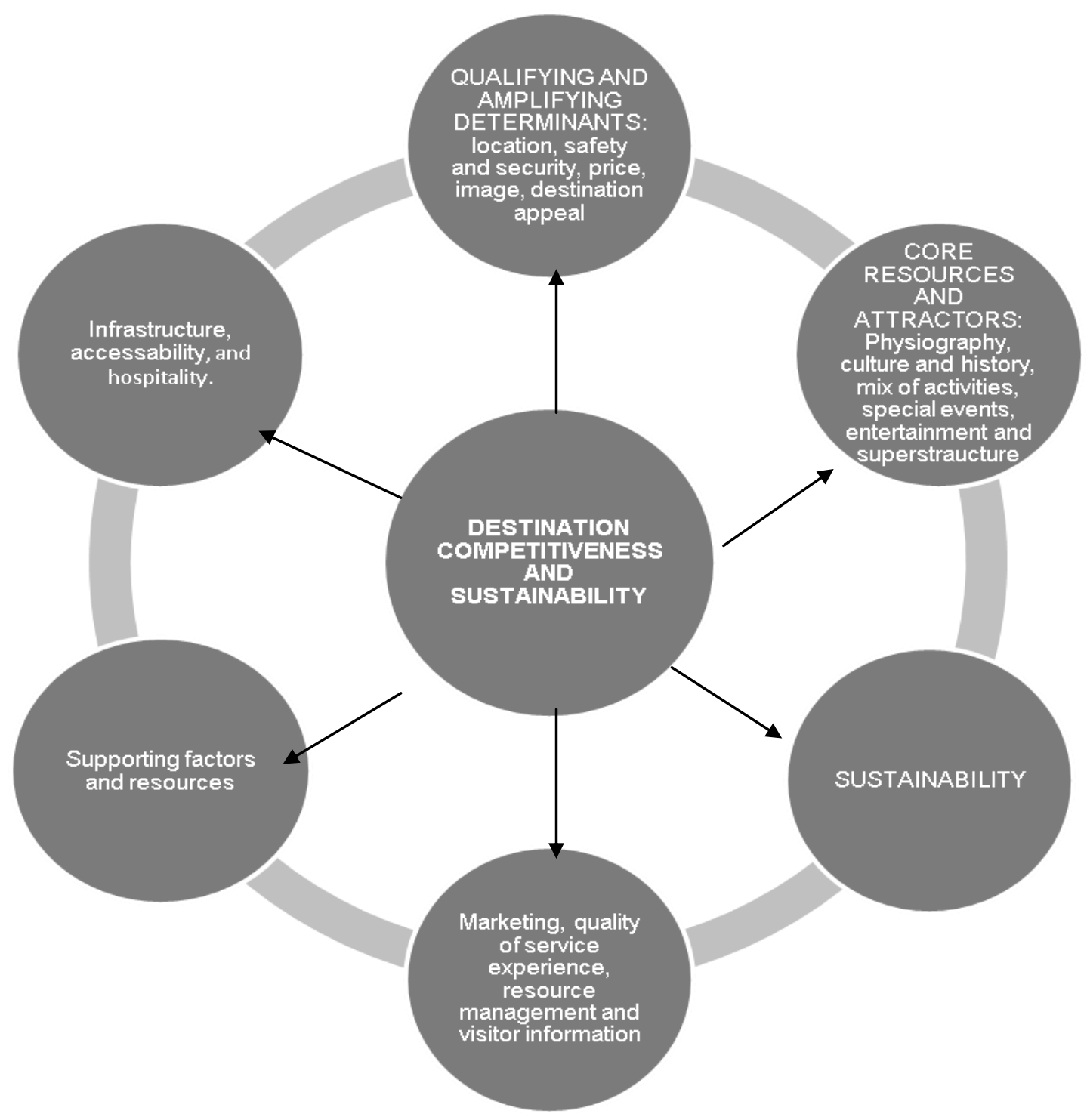

Source: Factors from Crouch and Ritchie (2003, P, 63)

Tourism competitiveness is also about providing better quality goods and services. Durban needs to provide its overall attractiveness and quality experiences that are better than those of other destinations in order to achieve competitive advantage. Durban can focus on improving its market position and share. Durban as a destination must integrate value added products to sustain it's resources. Core resources and attractors are the fundamental factors that visitors visit a destination. A destinations physiography, culture and history, which furnish a basic and powerful attracting, force for the prospective visitor. Creating memorable experiences can create a clear competitive advantage. Customer experience rather than customer service is a hallmark of new economic growth. Durban needs to build on the strength of a surf city. Entertainment is also a core resource attractor. A city like Melbourne in Australia, which similar to Durban stages theatre productions. Tourism superstructure is also a significant core attractor. A destination is visited because of its appeal.

Core resources and attractors must be supported supporting factors. A destination is competitive when transportation systems are effective and efficient, safe and clean. Easy accessibility to attractions is a 
competitive advantage. Operating sectors of tourism are responsible for high quality memorable experiences. Visitors need to feel welcome and that they are truly guests. Destination competitiveness also depends on tourism development and service experience. High quality service transactions are required. Durban's competitiveness depends on the core resources, attractors, supporting factors, resources, destination, policy, planning and development. Awareness and image of a destination can also qualify or amplify its competitiveness. This study should contribute to the development and sustainability of the tourism industry in the Durban area. The study is also intended to measure and assess Durban as a tourism destination. Establishing Durban's competitiveness factors would give recognition for long-term success and sustainability as well as improvements to the city of Durban as a destination. The core would be resources and attractions, which are why people visit destinations. Delivering a memorable experience for the tourist and qualifying and amplifying determinants that focus on location, safety, cost, interdependence, destination image and carrying capacity are vital in the management and marketing of a competitive tourism destination. Durban also has many natural and built resources, which need to be used to market a city that has great potential to compete with other cities globally. The application of a destination competitiveness model would lead to a series of improved and applied marketing strategies. Critical issues would be determined and innovative methods would be devised.

\section{Conclusion}

Destinations visitor attractions are a key factor to drawing tourists to an area. These factors influence the exciting a memorable destination experience. The physiography of a destination such as landscape, scenery and climate factors are contributing factors of visitor attractions. The physiography of a destination endows a destination with competitive appeal or creates barriers. Durban has a favorable climate all year round, which is attractive. Durban is also known for its sun, sea and sand. Climate and scenery are competitive factors as well. Durban boasts a rich mixture of cultures. The cultural and historical factors of a destination furnish intellectual satisfaction from visitors. Culture is a powerful dimension of attractiveness. The traditions and history of a destination tend to have greater drawing power for visitors outside the destination. High quality distinctive meals are a powerful element. Visitors visiting a destination participate in activities and leave with vibrant memories. Quality of uniqueness is an essential factor to heighten destination appeal. Events add to the core attractiveness of a tourism destination. Hallmark and mega events furnish a destination with a continuous stream of visitors. The host city should be necessary see destination. Core resources and attractors represent the pulling force. If resources are limited or substandard abundant core resources and attractors will be significantly constrained and their ability to pull tourists. Visitors are concerned with issues such a reliability, efficiency, safety and cleanliness. Durban requires a competitiveness model, which would support a long term marketing strategy, ensure the long term tourism and economic sustainability. Durban also has many natural and built resources, which need to be used to market a city that has great potential to compete with other cities globally.

Sustainability refers to the ability of a destination to maintain quality of its physical, social, cultural and environmental resources and natural capital. Durban also has many natural and built resources, which need to be used to market a city that has great potential to compete with other cities globally. The application of a destination competitiveness model would lead to a series of improved and applied marketing strategies. Critical issues would be determined and innovative methods would be devised. This study should contribute to the development and sustainability of the tourism industry in the Durban area. The study is also intended to measure and assess Durban as a tourism destination. Establishing Durban's competitiveness factors would give recognition for long-term success and sustainability as well as improvements to the city of Durban as a destination. The core would be resources and attractions, which are why people visit destinations.

\section{References}

Bowen, J., Kotler, P. \& Makens, J. (2003). Marketing for Tourism and Hospitality (3 $3^{\text {rd }}$ ed). CAB International. Brent, J. R. \& Ritchie, J. R. (2003). The Competitive Destination: A sustainable tourism perspective. CAB International.

Chen, S. J. \& Uysal, M. (2002). Market positioning analysis. Research Annals, 29(4), 988-1000.

Cole, B. (2012). Plans for Durban Tourism. The Sunday Tribune, July 29:5. 
Crouch, G. I. (2011). Destination Competitiveness: An analysis of determinant Attributes. The Journal of Travel Research, 50(1), 27-45.

Dwyer and Kim's integrative destination competitiveness model (2003).

George, R. (2008). Marketing Tourism in South Africa. (3 ${ }^{\text {rd }}$ ed), Pretoria: Van Schaik Publishers.

Goeldner, C., Ritchie, J. R. B. \& McIntosh, R. W. (2000). Tourism Principles, Practices, Philosophies (8th Ed). New York: John Wiley \& Sons, Inc.

Keyser, H. (2009). Developing Tourism in South Africa towards Competitive Destinations. Pretoria: Van Schaik.

Lockwood, A. \& Medlik, S. (2002). Tourism and Hospitality in the 21 ${ }^{\text {st }}$ Century. Elsevier Ltd.

Lee, B., Lee, C. C. K. \& Lee, Y. K. (2002). Korea's destination image formed by the world Cup. Research Annals, 32(4),839-850.

Macfarlane, I. Durban Tourism. (2012). Visitor industry strategy discussion. Durban: Government Printer.

Poon, A. (1993). Tourism Technology and Competitive Strategies. CAB International.

Republic of South Africa. The National Department of Tourism, 2011-2016. Medium-Term Strategic Plan. Pretoria: Government Printer.

Republic of South Africa. The National Department of Tourism, 2011. National Tourism Sector Strategy. Pretoria: Government Printer.

Republic of South Africa. South African Tourism, 2011-2013. The Marketing Tourism Growth Strategy for South Africa. Pretoria: Government Printer.

Republic of South Africa. Tourism Kwazulu-Natal, 2008-2012.Tourism Kwazulu-Natal Tourism Strategy. KwaZulu-Natal: Government Printer.

Republic of South Africa. Tourism KwaZulu-Natal, 2008. White Paper on the development and Promotion of Tourism KwaZulu-Natal. KwaZulu-Natal: Government Printer.

Republic of South Africa. South African Tourism, 2008-2010. The Marketing Growth Strategy for South Africa. Pretoria: Government Printer.

Republic of South Africa. National Department of Tourism, 2012-2013. Strategic Plan and Annual Performance Plan. Pretoria: Government Printer.

Republic of South Africa. Kwazulu-Natal Provincial Department of Economic Development and Tourism, 2012. New Master Plan. Pietermaritzburg: Government Printer.

Republic of South Africa. Department of Environmental Affairs and Tourism, 1996. The White Paper on The Development and Promotion of Tourism in South Africa. Government Gazette May 1996.

Saunder, G. (2003). Marketing for tourists. The Journal of Southern African Tourism. March/April.

Spain. (2009). The global tourism competitiveness report. Madrid: UNWTO Printer.

Spain. (2011). The global tourism competitiveness report. Madrid: UNWTO Printer.

Spain. (2013). The Travel and Tourism Competitiveness report. Madrid: UNWTO Printer.

Swarbrooke, J. (2001). The Development and Management of Visitor Attractions (1 ${ }^{\text {st }}$ Ed). Oxford: Butterworth- Heinemann.

Swarbrooke, J. (2002). The Development and Management of Visitor Attractions (2 ${ }^{\text {nd }}$ Ed). Oxford: Butterworth- Heinemann.

Yeoman, I. (2008). Tomorrow's Tourist. Elsevier Ltd. 